\title{
Fluoroquinolones susceptibility analysis of Arcobacter spp. isolated of fresh cheese, from the city of Guaranda
}

\author{
Riveliño Ramón Curay ${ }^{a}$, Israel Goyes ${ }^{a}$, Darwin Núñez Torres $^{a}$, Katherin Beltrán $^{a^{*}}$, \\ Favian Bayas Morejón ${ }^{a}$
}

${ }^{a}$ Universidad Estatal de Bolivar, Departamento de Investigación, Centro de Biotecnología, Campus Agropecuario "Laguacoto II”; mkbm27@ hotmail.com

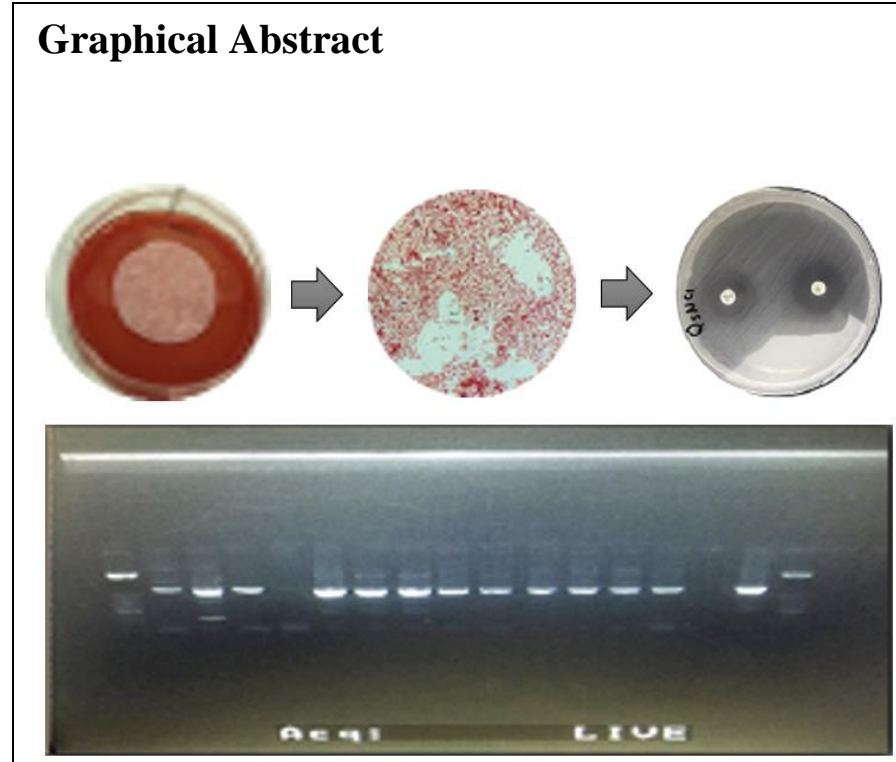

\section{Abstract.}

The Arcobacter genus is an emerging microorganism of free life that is widely distributed in the environment and forms micro intestinal biota of animals and humans. Most of these, are zoonotic, as is the case of Arcobacter butzleri, currently considered an emerging pathogen and transmitted by food, microorganism and of growing importance for public health. It should be noted that said microorganism in certain cases has presented resistance to antibiotics such as Fluoroquinolones (specific for $\varepsilon$-bacteria). Considering the previously described, the main of this investigation was to study of susceptibility to Fluoroquinolones by the Disco-Plate Diffusion technique for Arcobacter spp. isolated from fresh cheeses, obtained from the municipal markets of Guaranda (Ecuador). Fluoroquinolones are broad-spectrum chemotherapeutic agents, which constitute one of the most important contributions that can prevent or cure infectious diseases. For which, 100 samples of cheese were analyzed, 50 from the Bellavista market and 50 from the 10 November market, then Arcobacter was isolated by selective culture, DNA was extracted and then amplified by PCR. The type of analysis used was 
a descriptive statistical model where tests of analysis of means, percentages and frequencies were studied. After culture, 66 strains of Arcobacter were isolated from 47 samples, (25 strains from the Bellavista market; and 41 from the 10 November market, by PCR, resulting 26 isolates positive of the $16 \mathrm{~S}$ rRNA gene established by Figueras et al. (2012). In the susceptibility test to Fluoroquinolones, 2/26 cases, were found to be resistant to the bacteria, making up 7.69\%; 19/26 cases reflected an intermediate resistance to Arcobacter, these being $73.08 \%$; finally 5 / 26 cases were found to be susceptible, forming the remaining $19.23 \%$ The criteria used for the analysis were those established for Campylobacter according to the Clinical Laboratory and Standards Institute (CLSI 2010, M45-A2).

\section{Conclusions (optional)}

This work evidences the presence of Arcobacter isolates in cheeses susceptible to fluoroquinolones, but this does not take away the importance of sanitary control and implementation of good manufacturing practices and thus avoid food-borne infections to the consumer.

\section{References (mandatory)}

.Figueras, M.J, Levican, A., Collado, L. (2012). Updated 16S rRNA-RFLP method for the identification of all currently characterized Arcobacter spp. BMC Microbiol, 12: 292.

.CLSI. (2010). Performance standards for antimicrobial susceptibility testing M45-A2. Twenty-first informational supplement. Clinical and Laboratory Standard Institute, USA. 